\title{
Modelagem das perdas causadas por Sitophilus zeamais e Rhyzopertha dominica em trigo armazenado ${ }^{1}$
}

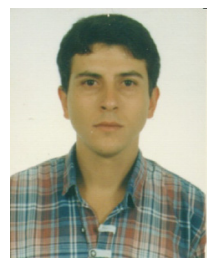

Arienilmar A. L. da Silva², Lêda Rita D'Antonino Faroni², Raul N. C. Guedes ${ }^{3}$, José H. Martins ${ }^{2} \&$ Marco A. G. Pimentel ${ }^{4}$

\footnotetext{
${ }^{1}$ Parte da Tese do primeiro autor apresentada à UFV para obtenção do título de Doutor em Engenharia Agrícola

2 DEA/UFV. CEP 36571-000, Viçosa, MG. E-mail: aals@uaimail.com.br (Foto), Ifaroni@ufv.br e jmartins@ufv.br

${ }^{3}$ DBA/UFV. CEP 36571-000, Viçosa, MG. E-mail: guedes@ufv.br

${ }^{4}$ Graduando de Agronomia/UFV. Viçosa, MG. E-mail: marco@vicosa.ufv.br
}

Protocolo 140 - 18/9/2002 - Aprovado em 20/5/2003

\begin{abstract}
Resumo: Modelaram-se as perdas associadas à infestação de $S$. zeamais e $R$. dominica em trigo armazenado. Durante 90 dias de armazenagem, avaliaram-se a população de insetos, a umidade dos grãos, o percentual de grãos danificados por insetos, o peso hectolítrico e a perda de matéria seca da massa de grãos, em temperaturas de 16 a $36{ }^{\circ} \mathrm{C}$. Segundo a Norma Brasileira de Classificação e Comercialização, o trigo que ultrapassar 1,5\% de grãos danificados é classificado como "abaixo do padrão" e os modelos calculam que seria necessária uma população de $S$. zeamais de 180 insetos $\mathrm{kg}^{-1}$ para se atingir o percentual de $1,5 \%$ de grãos danificados, associado a umedecimento de $0,13 \%$, redução no peso hectolítrico de $0,4 \mathrm{~kg} \mathrm{hL}^{-1}$ e perda de $0,7 \%$ de matéria seca. Para $R$. dominica, uma população de 64 insetos $\mathrm{kg}^{-1}$ leva a $1,5 \%$ de grãos danificados, juntamente com o umedecimento de $0,07 \%$, redução de $0,5 \mathrm{~kg} \mathrm{hL}^{-1}$ no peso hectolítrico e perda de $0,5 \%$ de matéria seca. Em populações de mesmo tamanho, $R$. dominica foi mais prejudicial que S. zeamais. Dentre os fatores de perda e classificação comercial do trigo, o percentual de grãos danificados foi o mais influenciado pelo crescimento populacional dos insetos.
\end{abstract}

Palavras-chave: Sitophilus zeamais, Rhyzopertha dominica, trigo, perdas, modelos

\section{Modeling of the losses caused by Sitophilus zeamais and Rhyzopertha dominica in stored wheat}

\begin{abstract}
The losses in wheat storage associated with infestation of $S$. zeamais and R. dominica were modeled. In the course of 90 days of storage, insect population, moisture content, percentage of weight loss of insect damaged grains, test weight per hectoliter and dry matter loss of wheat grains were evaluated at $16-36{ }^{\circ} \mathrm{C}$. In conformity with the Brazilian Classification and Commercialization Standards, the designation "below standard" is applied to wheat that contains more than $1.5 \%$ of insect damaged grains and the models predict that in case of $S$. zeamais a population of 180 insects $\mathrm{kg}^{-1}$ would be necessary to achieve $1.5 \%$ of damaged grains, associated with a moisture content of $0.13 \%$, test weight reduction of $0.4 \mathrm{~kg} \mathrm{hL}^{-1}$ and $0.7 \%$ of dry matter loss. For $R$. dominica, 64 insects $\mathrm{kg}^{-1}$ would be necessary to achieve $1.5 \%$ damaged grains, associated with a moisture content of $0.07 \%$, test weight reduction of $0.5 \mathrm{~kg} \mathrm{hL}^{-1}$ and $0.5 \%$ of dry matter loss. For equal size populations, the $R$. dominica was more harmful than S. zeamais. Among loss, grade and class factors for wheat, percent weight loss of insect damaged grains was more affected by the insect population growth.
\end{abstract}

Key words: Sitophilus zeamais, Rhyzopertha dominica, stored wheat, losses, models

\section{INTRODUÇÃO}

Os insetos de grãos armazenados têm sido extensivamente controlados por métodos químicos há décadas, mas as crescentes limitações ao uso de inseticidas convencionais têm incentivado as pesquisas sobre sistemas de controle integrado, envolvendo métodos químicos e não-químicos, aplicados na seqüência e no momento apropriado para se alcançar os resultados desejados (Harein \& Davis, 1992; Schöller et al., 1997). Segundo Onstad (1987), o controle deveria ser feito quando a população estabelecesse o nível cujas perdas fossem maiores que o custo de controle; portanto, a relação entre uma infestação e as perdas que ela causa ao longo do armazenamento, deve ser caracterizada para que, então, se possa realizar estudos econômicos acerca dos métodos de controle. Além disso, o estudo da relação entre o tamanho da população de insetos e 
as perdas vai aprimorar os modelos de simulação e os sistemas especialistas em manejo de pragas de grãos armazenados. Esse estudo também poderá auxiliar no aperfeiçoamento das Normas de Classificação e Comercialização do Trigo, com maior coerência entre os níveis dos fatores de classificação.

As perdas pós-colheita em regiões tropicais são altamente variáveis, sendo possível encontrar-se casos em que as perdas variam de 0 a $100 \%$ (Haines, 1995). Pelo menos $10 \%$ das perdas durante o armazenamento são causadas diretamente pelo ataque de insetos (Sinha, 1995). Esses insetos não apenas consomem grande quantidade de grãos como, também, reduzem sua qualidade, por que danificam e alteram o ambiente da massa, favorecendo outros fatores de deterioração, como os fungos e a respiração dos grãos. Também contaminam os grãos com suas exúvias, excrementos e despojos, aumentam os níveis de ácidos graxos livres, contaminando-os com ácido úrico, causam odores, empobrecem o rendimento e a qualidade das farinhas (Brooker et al., 1992; Pedersen, 1992; Faroni, 1995; White, 1995).

A redução no valor de mercado é baseada nas perdas em quantidade e em qualidade. Perdas em quantidade são de maior importância em regiões tropicais, onde os insetos têm um ambiente próximo do ótimo de crescimento durante a maior parte do ano (Harein \& Davis, 1992). A perda de massa é oficialmente avaliada pelo mercado de trigo por meio da medida do peso hectolítrico. A Norma Brasileira de Classificação e Comercialização do trigo permite, no mínimo, $78,75 \mathrm{e} 70 \mathrm{~kg} \mathrm{hL}^{-1}$ para os tipos 1, 2 e 3, respectivamente, com teor de umidade de 13\% b.u. (Brasil, 1999). Para se verificar a perda de qualidade, diversos testes podem ser empregados, como teor de umidade, percentual de grãos danificados por inseto, teor de fragmentos de insetos na farinha, susceptibilidade à quebra e teste de germinação (Brooker et al., 1992). Quanto ao teor de umidade, a norma brasileira permite o valor máximo de $13 \%$ para todos os tipos e, com relação ao percentual de grãos danificados, o máximo permitido é de $0,5,1,0$ e 1,5\%, em massa de grãos danificados por insetos para os tipos 1, 2 e 3, respectivamente (Brasil, 1999). $\mathrm{O}$ trigo que não atender às exigências para o tipo 3 é classificado como "abaixo do padrão". Quanto aos demais fatores de qualidade, eles não fazem parte da norma brasileira nem das internacionais.

Objetivou-se obter, com esta pesquisa, modelos matemáticos que estabeleçam a relação entre o crescimento populacional das pragas do trigo armazenado, Sitophilus zeamais (Motschulsky) (Coleoptera: Curculionidae) e Rhyzopertha dominica (Fabricius) (Coleoptera: Bostrichidae) e as perdas, em quantidade e qualidade, consideradas pelas normas internacionais de comercialização do trigo.

\section{MATERIAL E MÉTODOS}

Utilizou-se um delineamento experimental inteiramente casualizado, em esquema fatorial $8 \times 7 \times 6 \times 2$, sendo oito níveis iniciais de infestação, sete períodos de armazenagem, seis condições climáticas e duas espécies de inseto, S. zeamais e $R$. dominica, com três repetições, resultando em 672 tratamentos e 2.016 unidades experimentais.

As unidades experimentais consistiram de potes de vidro com livre circulação de gases, onde foi colocado $1,5 \mathrm{~kg}$ de trigo limpo, com teor de umidade de $11,1 \%$ b.u.. O peso hectolítrico inicial foi de $78,42 \mathrm{~kg} \mathrm{hL}^{-1}$. Os potes foram infestados com populações de $0,2,4,6,8,10,12$ e 14 insetos adultos de cada espécie, em tratamentos separados, e depois foram armazenados em câmaras climáticas, e o crescimento populacional ocorreu nas seguintes combinações de temperatura e umidade relativa: $16^{\circ} \mathrm{C}$ e $63 \%, 20^{\circ} \mathrm{Ce} 65 \%, 24^{\circ} \mathrm{C}$ e $67 \%, 28^{\circ} \mathrm{Ce} 68,5 \%, 32^{\circ} \mathrm{Ce}$ $70 \%, 36{ }^{\circ} \mathrm{C}$ e $71 \%$. Essas combinações visaram igualar o umedecimento higroscópico para todos os tratamentos, para que se pudesse quantificar o umedecimento causado exclusivamente pelas infestações. Com tais combinações, os grãos poderiam atingir o teor de umidade de equilíbrio de $13 \%$ b.u., conforme a equação de Henderson, modificada por Thompson, (Brooker et al., 1992), para trigo mole. O intervalo de temperaturas, de 16 a $36^{\circ} \mathrm{C}$, contém temperatura ótima para o desenvolvimento das duas espécies (Howe, 1950; Faroni \& García-Mari, 1992; Hwang et al., 1983; Throne, 1994).

Os potes infestados foram armazenados por períodos de 0 , $15,30,45,60,75$ e 90 dias e, no final de cada um, foram avaliadas a população de insetos adultos e as perdas quantitativas e qualitativas atualmente consideradas pelas normas de comercialização do trigo (Brasil, 1999). Para se conhecer a perda em quantidade, avaliou-se a perda de matéria seca. Avaliaramse o teor de umidade, o peso hectolítrico e o percentual de grãos danificados por insetos, para se verificar a perda em qualidade.

Para avaliação do crescimento populacional, o trigo de cada unidade experimental foi peneirado em um conjunto de peneiras de malha de arame para separar os insetos dos grãos e do pó. A primeira peneira, com malha de $1,41 \mathrm{~mm}$ (USS 14, Tyler 12), reteve os grãos e a segunda, com malha de 0,59 mm (USS 30, Tyler 28), inibiu os insetos adultos e os separou do pó.

Para relacionar o crescimento populacional e as perdas em quantidade, avaliou-se a perda de matéria seca, com base na massa e no teor de umidade da massa de grãos, antes e depois de cada período de armazenagem. Antes de se iniciar a armazenagem sob infestação, foram determinados a massa e o teor de umidade do trigo de cada unidade experimental. A massa variou de 1.500 a $1.515 \mathrm{~g}$ e depois, de cada período, os grãos foram separados do pó e dos insetos, para se ter a massa e o teor de umidade novamente determinados.

Para se relacionar o crescimento populacional e as perdas em qualidade, foram feitos testes de teor de umidade, peso hectolítrico e percentual de grãos danificados por insetos. Retiraram-se amostras da massa de grãos peneirada para a realização de cada teste, em três repetições. Para a determinação do teor de umidade, utilizou-se o método padrão de estufa a 105 $\pm 3{ }^{\circ} \mathrm{C}$, por $24 \mathrm{~h}$ (Brasil, 1992). Para se determinar o peso hectolítrico, utilizou-se uma balança da marca Dallemole, com capacidade para um quarto de litro e, para o teste de grãos danificados por insetos, coletaram-se e se pesaram amostras de 100 grãos de trigo, inspecionados visualmente, sendo os danificados separados e pesados, e o resultado expresso como percentagem em massa. Esse teste é uma adaptação do teste de sementes danificadas por insetos (Brasil, 1992) que expressa o resultado como percentagem em número de grãos.

A redução do peso hectolítrico decorrente do umedecimento higroscópico do trigo, durante o armazenamento, foi medida 
pela diferença de peso entre os tratamentos infestados e os sem infestação e, assim, foi possível se isolar o umedecimento e a redução de peso hectolítrico causado pelas populações de insetos.

Para relacionar as perdas em quantidade e qualidade com o crescimento populacional ajustou-se, por meio de regressão não-linear, o modelo matemático:

$$
\mathrm{Y}=\alpha \mathrm{X}^{\beta}
$$

em que $\mathrm{Y}$ representa a perda em umedecimento, danos por inseto, peso hectolítrico ou matéria seca; X é a população final de $S$. zeamais ou $R$. dominica (insetos adultos $\mathrm{kg}^{-1}$ de trigo); $\alpha \mathrm{e} \beta$ são coeficientes. Utilizou-se o programa STATISTICA for Windows (STATISOFT, 1993) para a análise de regressão.

\section{RESULTADOS E DISCUSSÃO}

Os modelos apresentados a seguir compreendem populações que vão de zero a milhares de insetos por quilograma de trigo, cujo intervalo foi importante para a visualização da linha de tendência e identificação do modelo mais apropriado. No entanto, do ponto de vista prático, as perdas limites estão associadas a densidades populacionais de apenas algumas centenas de insetos $\mathrm{kg}^{-1}$.

\section{Perdas causadas por $S$. zeamais}

As Figuras 1, 2, 3, e 4 mostram o efeito da população de insetos sobre, respectivamente, o teor de umidade, o percentual de grãos danificados, o peso hectolítrico e a perda de matéria seca do trigo. Hardman (1978) para validar seu modelo, infestou 696 g de trigo com 100 adultos de $S$. oryzae, o que corresponde a 143 insetos $\mathrm{kg}^{-1}$. O trigo com teor de umidade de $12,4 \%$ b.u. foi armazenado na temperatura de $23{ }^{\circ} \mathrm{C}$. $\mathrm{O}$ autor não mencionou a umidade relativa nem a possibilidade de umedecimento higroscópico, mas seu modelo predisse um umedecimento de 3,6 pontos percentuais em 90 dias para uma população de 7.333 insetos $\mathrm{kg}^{-1}$, valor semelhante ao predito pelo modelo apresentado neste trabalho (equação correspondente à curva da Figura $1)$.

Quanto ao percentual de grãos danificados (Figura 2), o modelo de Longstaff (1981) para S. aryzae em trigo tratado com

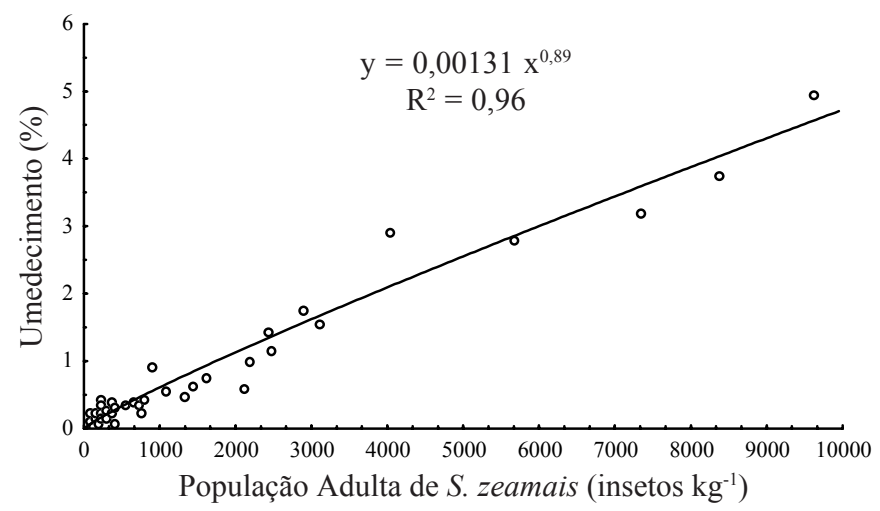

Figura 1. Valores observados (círculos) e preditos (linha) para o umedecimento em função da população final de $S$. zeamais em trigo

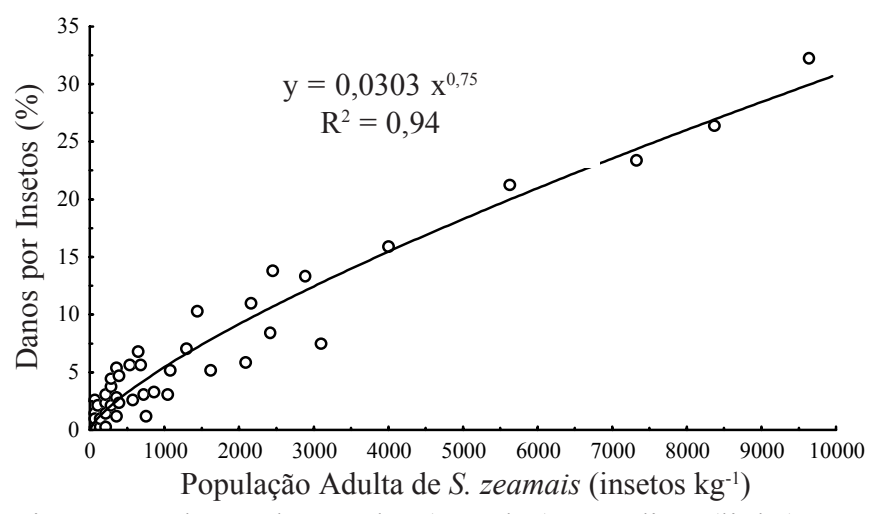

Figura 2. Valores observados (círculos) e preditos (linha) para os danos, em função da população final de $S$. zeamais em trigo

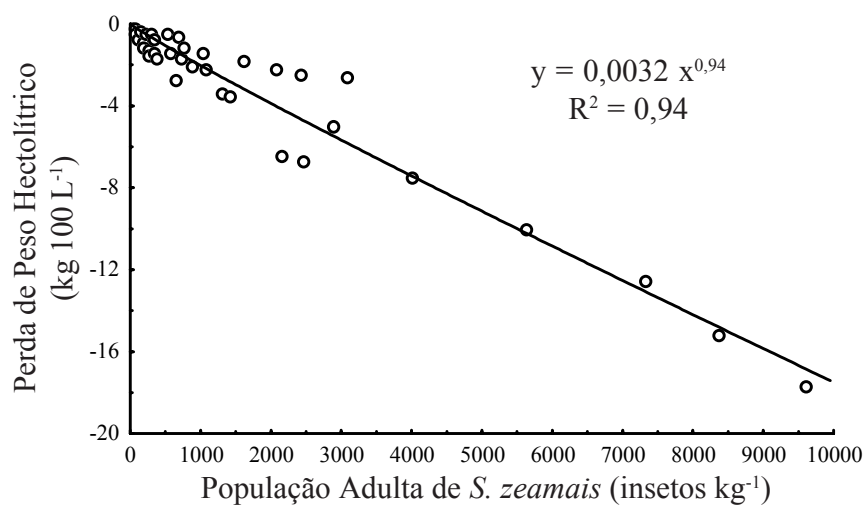

Figura 3. Valores observados (círculos) e preditos (linha) para a perda de peso hectolítrico, em função da população final de S. zeamais em trigo

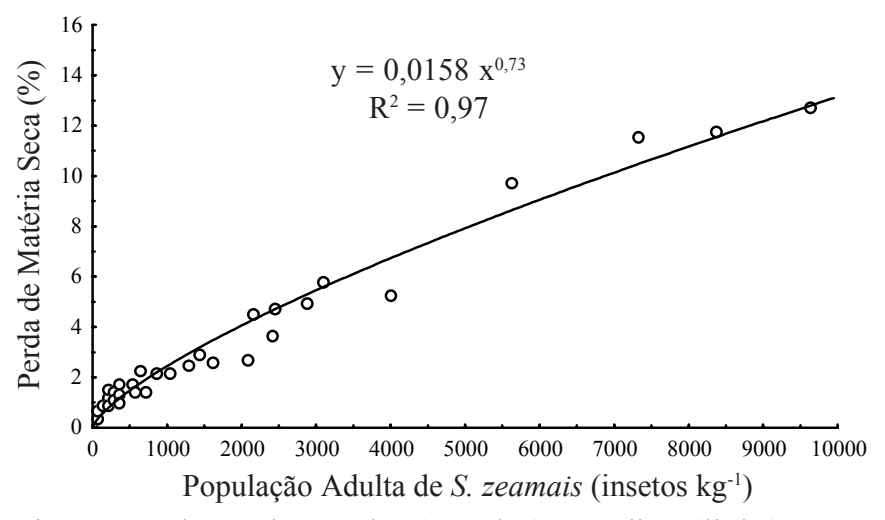

Figura 4. Valores observados (círculos) e preditos (linha) para a perda de matéria seca, em função da população final de $S$. zeamais em trigo

inseticida protetor, armazenado a $24^{\circ} \mathrm{C}$, predisse uma quantidade de aproximadamente $10^{4}$ grãos danificados para uma população de 727 insetos $\mathrm{kg}^{-1}$. Considerando que $10^{4}$ grãos danificados equivalem a mais ou menos $200 \mathrm{~g}$, o modelo da Figura 2 prevê $200 \mathrm{~g}(2 \%)$ de grãos danificados para uma população de 264 insetos $\mathrm{kg}^{-1}$, ou seja, uma população quase três vezes menor causou o mesmo dano na ausência de inseticida protetor.

Quanto à relação entre a população de $S$. zeamais e a redução no valor do peso hectolítrico, não foram encontradas pesquisas sobre o assunto. $\mathrm{O}$ modelo apresentado na Figura 3 prevê que 
uma queda de $3 \mathrm{~kg} \mathrm{hl}^{-1}$ está associada a uma infestação de 1.520 insetos $\mathrm{kg}^{-1}$.

Neste experimento, estudou-se a perda em quantidade baseada na matéria seca, a fim de que os resultados pudessem ser aplicados a grãos com teores de umidade diferentes, mas se deve observar que o inseto consome água junto com a matéria seca do grão e, se são consumidas água e matéria seca na mesma proporção, não importa a base em que são apresentados os resultados. Por exemplo, em um silo com 100 t de trigo com 13\% de teor de umidade, há $87 \mathrm{t}$ de matéria seca e $13 \mathrm{t}$ de água. Conforme o modelo apresentado na Figura 4, uma infestação de 295 inseto $\mathrm{kg}^{-1}$ causa perda de $1 \%$ de matéria seca. Se se considerar que, juntamente com $1 \%$ de matéria seca, é consumido $1 \%$ de água, ter-se-á uma perda de massa total equivalente a 1\% das $100 \mathrm{t}$, ou seja, $1 \mathrm{t}$.

Conforme os modelos apresentados nas Figuras de 1 a 4, seria necessária uma população de $S$. zeamais de 180 insetos $\mathrm{kg}^{-1}$ de trigo para que se atingisse um percentual de grãos danificados de $1,5 \%$, juntamente com umedecimento de 0,13 ponto percentual, uma redução de $0,41 \mathrm{~kg} \mathrm{hL}^{-1}$ no peso hectolítrico e perda de $0,7 \%$ de matéria seca.

\section{Perdas causadas por $R$. dominica}

As Figuras 5, 6, 7 e 8 mostram o efeito do crescimento da população de $R$. dominica sobre, respectivamente, o teor de umidade, o percentual de grãos danificados, o peso hectolítrico e a perda de matéria seca do trigo.

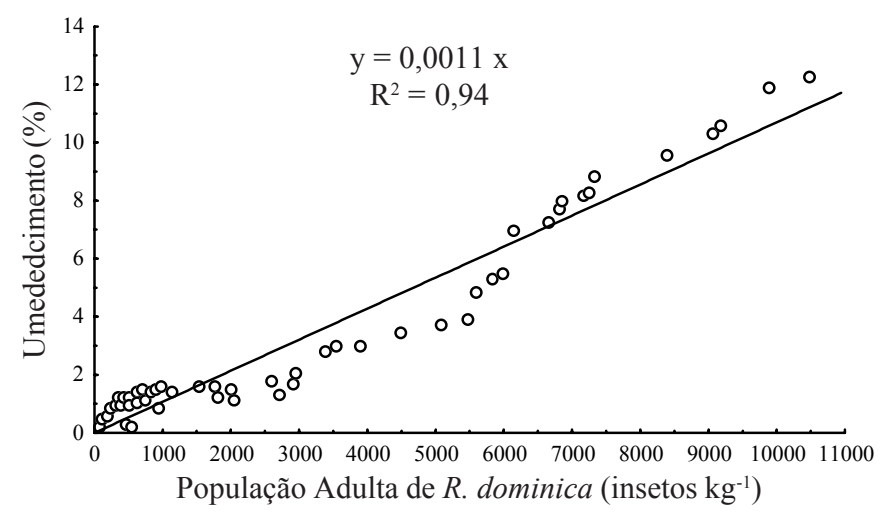

Figura 5. Valores observados (círculos) e preditos (linha) para o umedecimento, em função da população final de $R$. dominica em trigo

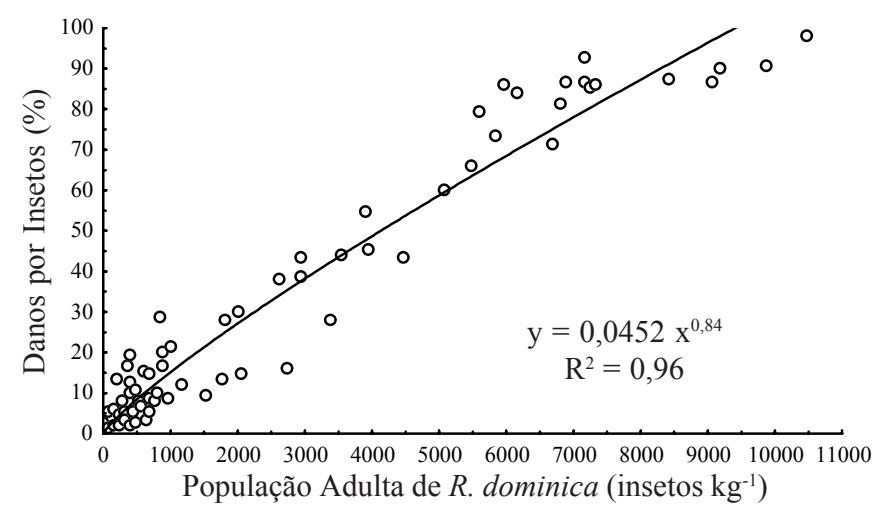

Figura 6. Valores observados (círculos) e preditos (linha) para os danos, em função da população final de $R$. dominica em trigo

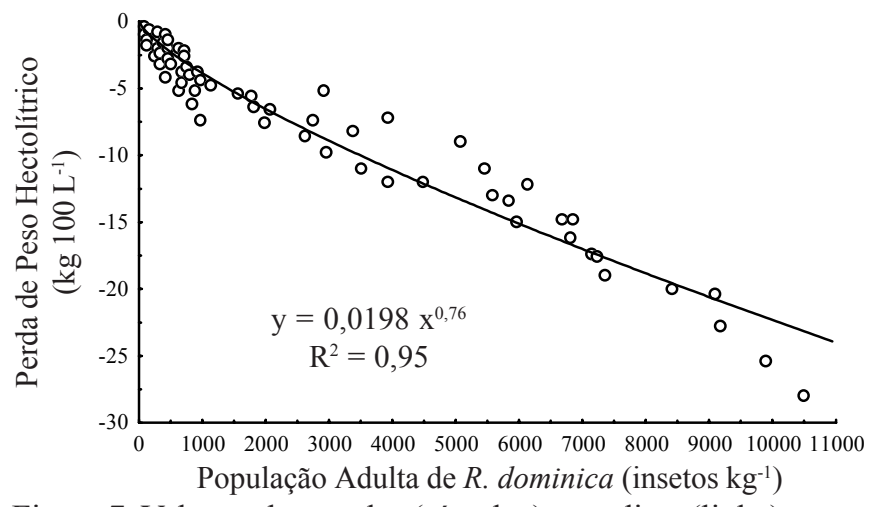

Figura 7. Valores observados (círculos) e preditos (linha) para a perda de peso hectolítrico em função da população final de $R$. dominica em trigo

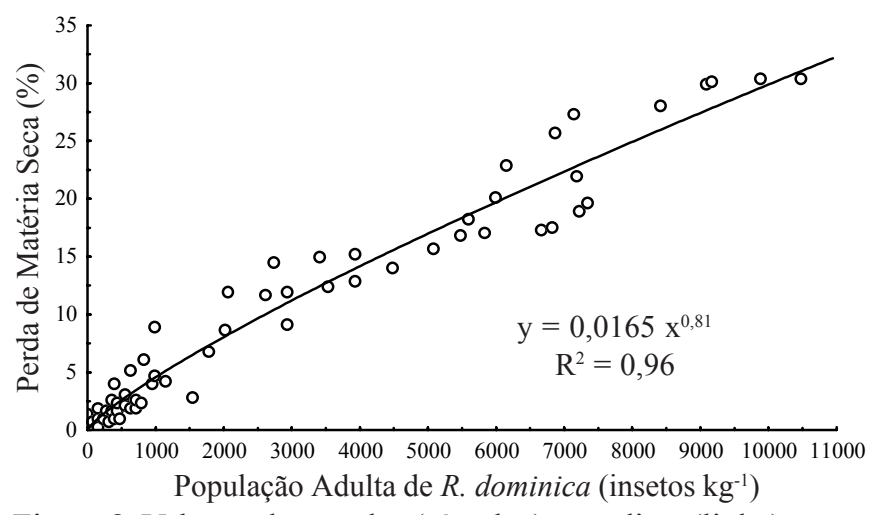

Figura 8. Valores observados (círculos) e preditos (linha) para a perda de matéria seca, em função da população final de $R$. dominica em trigo

Segundo o modelo apresentado na Figura 5, o umedecimento de um ponto percentual está associado a uma população de 935 insetos $\mathrm{kg}^{-1}$ de trigo.

Flinn \& Hagstrum (2001) observaram 148 grãos danificados por inseto por $100 \mathrm{~g}$ de trigo para uma infestação de aproximadamente 265 insetos $\mathrm{kg}^{-1}$. Considerando-se que 1.000 grãos sadios pesam $37 \mathrm{~g}$ (Hoseney \& Faubion, 1992) e que grãos danificados por inseto perderam pelo menos $1 / 4$ de sua massa, deduz-se que aquele valor corresponde a $4,1 \%$, em massa, de grãos danificados por inseto. O modelo apresentado na Figura 6 prediz $4,96 \%$, indicando semelhança entre os resultados.

Quanto à redução no valor do peso hectolítrico, o modelo apresentado na Figura 7 prediz que uma diferença de $3 \mathrm{~kg} \mathrm{hL}^{-1}$, capaz de alterar a classificação do trigo do tipo $1\left(78 \mathrm{~kg} \mathrm{hL}^{-1}\right)$ para o tipo $2\left(75 \mathrm{~kg} \mathrm{hL}^{-1}\right)$, está associada a uma infestação de 935 insetos $\mathrm{kg}^{-1}$.

Conforme os modelos apresentados, seria necessária uma população de $R$. dominica de 64 insetos $\mathrm{kg}^{-1}$ de trigo para que se atingisse um percentual de grãos danificados de $1,5 \%$, juntamente com umedecimento de 0,07 ponto percentual, uma redução de $0,5 \mathrm{~kg} \mathrm{hL}^{-1}$ no peso hectolítrico e perda de $0,5 \%$ de matéria seca (Figura 8).

Quanto à comparação dos resultados entre as duas espécies, para populações de 0 a 100 insetos $\mathrm{kg}^{-1}$, os valores de perda de matéria seca são semelhantes, mas as perdas com umedecimento, com peso hectolítrico e com grãos danificados, foram 
aproximadamente duas vezes maiores para $R$. dominica, devido às diferenças de comportamento alimentar das larvas das espécies. Ambas podem ter consumido a mesma quantidade de matéria seca, mas a larva de $S$. zeamais se mantém oculta dentro de um grão aparentemente sadio, enquanto a larva de $R$. dominica se desenvolve em um grão já danificado. Deste modo, em grãos infestados por $R$. dominica, os danos ocorrem mais cedo e, em conseqüência, o umedecimento e a redução de peso hectolítrico também.

\section{CONCLUSÕES}

1. Para populações de mesmo tamanho, a espécie $R$. dominica mostrou-se maior causadora de perdas em trigo armazenado que a espécie $S$. zeamais. Esta diferença aumentou com o crescimento da população.

2. Em infestações com 0 a 100 insetos $\mathrm{kg}^{-1}$, para valores semelhantes de perda de matéria seca entre as espécies, as perdas com umedecimento, peso hectolítrico e grãos danificados, foram aproximadamente duas vezes maiores para $R$. dominica, em comparação com $S$. zeamais.

3. Dentre os fatores de perda de qualidade e classificação comercial do trigo, o fator percentual de grãos danificados mostrou-se mais sensível ao crescimento populacional.

4. Os modelos desenvolvidos apresentaram excelentes coeficientes de correlação e podem ser usados como ferramentas no estudo da eficiência dos métodos de controle de pragas e das perdas que elas causam à quantidade e à qualidade do trigo armazenado.

\section{LITERATURA CITADA}

Brasil. Ministério da Agricultura, Departamento Nacional de Produção Vegetal, Divisão de Sementes e Mudas. Regras para Análise de Sementes. Brasília: [s.n.], 1992.365p.

Brasil. Ministério da Agricultura e do Abastecimento. Norma de identidade e qualidade do trigo. Instrução Normativa $\mathrm{n}^{\circ}$.1, de 27 de janeiro de 1999. Diário Oficial, 29.01.99. 6p. 1999.

Brooker, D.B.; Bakker-Arkema, F.W.; Hall, C.H. Drying and storage of grains and oilseeds. Westport, CT: AVI, 1992. 450p.

Faroni, L.R.A. Pragas e métodos de controle. In: Silva, de J. e S. Pré-Processamento de Produtos Agrícolas. Juiz de Fora, MG: Instituto Maria, 1995.350p.

Faroni, L.R.A.; García-Mari, F. Influencia de la temperatura sobre los parámetros biológicos de Rhyzopertha dominica (F.). Boletin Sanitario de los Vegetales e Plagas, n.18, p.455-467, 1992.

Flinn, P.W.; Hagstrum, D.W. Augmentative releases of parasitoid wasps in stored wheat reduces insect fragments in flour. Journal of Stored Products Research, v.33, p.179$186,2001$.
Haines, C.P. Grain storage in the tropics. In: Jayas, D.; White, N.D.G.; Muir, W.E. (eds.). Stored-grain ecosystems. New York: M. Dekker, 1995. p.169-197.

Hardman, J.M. A logistic model simulating environmental changes associated with the growth of populations of rice weevils Sitophilus Øryzae, reared in small cells of wheat. Journal of Applied Ecology, v.15, n.1, p.65-87, 1978.

Harein, P.K.; Davis, R. Control of stored-grain insects. In: Sauer, D.B. (ed.). Storage of Cereal Grains and their Products. St. Paul: American Association of Cereal Chemists, 1992. p.491534.

Hoseney, R.C.; Faubion, J.M. Physical properties of cereal grains. In: Sauer, D.B. (ed.). Storage of cereal grains and their products. St. Paul: American Association of Cereal Chemists, 1992. p.1-38.

Howe, R.W. The development of Rhyzopertha dominica (F.) (Coleoptera: Bostrichidae) under constant conditions. The Entomologist's Monthly Magazine, London, v.86, n.11, p.1$5,1950$.

Hwang, J.S.; Hsieh, F.K.; Kung, K.S. Influences of temperature and relative humidity on the development and reproduction of the maize weevil, Sitophilus zeamais Motschulsky. Plant Protection Bulletin, n.24, p.41-52, 1983.

Longstaff, B.C. The manipulation of population growth of a pest species, an analytical approach. Journal of Applied Ecology, Malden, v.18, p.727-736, 1981.

Onstad, D.W. Calculation of economic-injury levels and economics thresholds for pest management. Journal of Economic Entomology, Lanham, v.80, n.2, p.297-303, 1987.

Pedersen, J.R. Insects: identification, damage and detection. In: Sauer, D.B. (ed.). Storage of Cereal Grains and their Products. St. Paul: American Association of Cereal Chemists, 1992. p.435-491.

Schöller, M.; Prosell, S.; Al-Kirshi, A.G.; Reichmuth, C.H. Towards biological control as a major component of integrated pest management in stored product protection. Journal of Stored Products Research, Oxford, v.33, n.1, p.81-97, 1997.

Sinha, R.N. The stored-grain ecosystem. In: Jayas, D.; White, N.D.G.; Muir, W.E. (eds.). Stored-grain ecosystems. New York: M. Dekker, 1995. p.1-33.

STATISOFT, Inc. STATISTICA for Windows, release 4.2., Cary: SAS Institute, NC, USA, 1993.

Throne, J.E. Life history of immature maize weevils Sitophilus zeamais Motschulsky (Coleoptera: Curculionidae) on corn stored at constant temperatures and relative humidities in the laboratory. Environmental Entomology, College Park, v.23, n.6, p.1459-1471, 1994.

White, N.D.G. Insects, mites and insecticides in stored-grain ecosystems. In: Jayas, D.; White, N.D.G.; Muir, W.E. (eds.). Stored-grain ecosystems. New York: M. Dekker, 1995. p.256288. 